Ponteconvo, G. \& Sermonti, G. (1954). J. gen. Microbiol. 11, 94-104.

\title{
Parasexual Recombination in Penicillium chrysogenum
}

\author{
By G. PONTECORVO AND G. SERMONTI \\ Department of Genetics, University of Glasgow
}

SUMMARY: Roper's (1952) technique for the isolation in filamentous fungi of strains carrying in their hyphae diploid nuclei heterozygous for known markers has been applied with minor modifications to a third species: Penicillium chrysogenum. One of these modifications is the use of 'dwarf' (stunted growth) mutants for growing balanced heterokaryons. Heterozygous diploid strains of $\boldsymbol{P}$. chrysogenum behave like those of the other two species in yielding, vegetatively, new strains with recombined properties. This behaviour can be marshalled for the deliberate breeding of improved industrial strains.

In two species of filamentous fungi, Aspergillus nidulans (Roper, 1952; Pontecorvo \& Roper, 1952, 1953; Pontecorvo, Tarr Gloor \& Forbes, 1954) and Aspergillus niger (Pontecorvo, 1952; Pontecorvo, Roper \& Forbes, 1953), recombination between properties of different strains may take place outside, or in the absence of, a sexual cycle. Processes leading to gene recombination otherwise than via sexual reproduction are called 'parasexual' (Pontecorvo, $1953 a$ ). The present paper reports the discovery of a parasexual cycle in a third species, Penicillium chrysogenum, the mould used for the industrial production of penicillin. This discovery was the outcome of the application, with minor modifications, to this species of the techniques developed for the other two species.

The differences in properties used for the present work (colours of conidia, growth rates, colony morphology and nutritional requirements) were chosen exclusively for their convenience as experimental markers. The discovery that recombination occurs in respect of these properties makes it certain that it also occurs in respect of inherited properties of other kinds. Clearly, this knowledge makes possible the deliberate breeding of improved strains for penicillin production. A preliminary report of the work in this paper has been published (Pontecorvo \& Sermonti, 1953).

\section{The production of marked strains}

Unless explicitly stated, the techniques used in the present work are the same as those used as a routine for Aspergillus nidulans (Pontecorvo, 1953b) and applied to $A$. niger (Pontecorvo et al. 1953).

Media. Minimal medium (MM): a modified Czapek-Dox. Complete Medium (CM): a complex medium containing yeast extract, casein hydrolysate, etc. Incubation was at $26^{\circ}$.

Organisms. Two starting strains of Penicillium chrysogenum were used; one with white conidia, turning very pale green after long incubation at room temperature, and one with yellow-brown conidia. The former, kindly supplied by Dr J. C. Calam (Imperial Chemical Industries, Manchester) was a mutant obtained after nitrogen mustard treatment. It is designated here with the 
symbol $w$. The yellow strain (symbol $y$, code no. 1086) was obtained previously by one of us (G.S.) after ultraviolet irradiation of strain Q176.47.1564. Both were prototrophs, i.e. able to grow well on medium MM, like the green-spored strain $Q 176$, to which both ultimately traced back.

The marked strains required for the present work were strains differing from the wild type in three pairs of alternative characters and from each other in six pairs. Two pairs (white versus green conidia, yellow versus green conidia) were already available in the two starting strains mentioned above. The other four pairs were obtained by successive ultraviolet irradiations and they consisted either in differences in nutritional requirements or differences in growth rates (e.g. dwarf versus normal colony size).

Table 1. Results of ultraviolet irradiation (4 min. at $30 \mathrm{~cm}$.) of dishes of CM agar plated with about 1000 conidia each

Mutants among isolates

\begin{tabular}{|c|c|c|c|c|c|c|c|c|}
\hline \multicolumn{2}{|c|}{ Strain irradiated } & \multirow{3}{*}{$\begin{array}{c}\text { Viable } \\
\text { counts } \\
(\%)\end{array}$} & \multirow{3}{*}{$\begin{array}{c}\text { Colonies } \\
\text { isolated } \\
\text { (No.) }\end{array}$} & \multicolumn{3}{|c|}{ Nutritional } & \multirow{2}{*}{\multicolumn{2}{|c|}{ Dwarf }} \\
\hline Code & Colour and & & & & Code & Additional & & \\
\hline No. & requirements & & & No. & No. & requirements & No. & Code No. \\
\hline$w$ & $\begin{array}{l}\text { White, no } \\
\text { requirements }\end{array}$ & 2 & 238 & $\mathbf{3}$ & $\begin{array}{l}4 w \\
7 w \\
8 w\end{array}$ & $\begin{array}{l}\mathrm{NO}_{2}^{-} \\
\text {Thiosulphate } \\
\text { Pyridoxine }\end{array}$ & - & - \\
\hline$y$ & $\begin{array}{l}\text { Yellow, no } \\
\text { requirements }\end{array}$ & $\mathbf{5}$ & 160 & $\mathbf{3}$ & $\begin{array}{l}19 y \\
22 y \\
38 y\end{array}$ & $\begin{array}{l}\text { Thiosulphate } \\
\text { Hypoxanthine } \\
\mathbf{N O}_{\mathbf{2}}^{-}\end{array}$ & - & - \\
\hline $22 y$ & $\begin{array}{l}\text { Yellow, } \\
\text { hypoxanthine }\end{array}$ & 17 & 325 & 4 & $\begin{array}{l}22 y 5 \\
22 y 13 \\
22 y 14 \\
22 y 15\end{array}$ & $\begin{array}{l}\mathrm{NH}_{2} \text { groups } \\
\text { Methionine } \\
\text { Arginine } \\
\text { Anthranilic } \\
\text { acid }\end{array}$ & $\mathbf{1}$ & $22 y d w 1$ \\
\hline $7 w$ & $\begin{array}{l}\text { White, } \\
\text { thiosulphate }\end{array}$ & 6 & 150 & $\mathbf{3}$ & $\begin{array}{l}7 w 13 \\
7 w 16 \\
7 w 32\end{array}$ & $\begin{array}{l}\text { Hypoxanthine } \\
\text { Adenine } \\
\text { Hypoxanthine }\end{array}$ & 2 & $\begin{array}{l}7 w d w 4 \\
7 w d w 5\end{array}$ \\
\hline $38 y$ & Yellow, $\mathrm{NO}_{2}^{-}$ & $0 \cdot 2$ & 125 & 2 & $\begin{array}{l}38 y 2 \\
38 y 3\end{array}$ & $\begin{array}{l}\text { Peptone } \\
\text { Thiosulphate }\end{array}$ & $\mathbf{1}$ & $38 y d w 6$ \\
\hline
\end{tabular}

Suspensions of $10^{4}$ conidia $/ \mathrm{ml}$. were spread in volumes of $0 \cdot 1 \mathrm{ml} . / \mathrm{plate}$ (1000 conidia) over the agar surface of a series of Petri dishes containing CM agar. The dishes were irradiated by exposing them to an Hanovia XI lowpressure mercury lamp for $4 \mathrm{~min}$. at $30 \mathrm{~cm}$. distance. Colonies which grew up (random sample) after such treatment (Table 1) were isolated and screened for mutants with additional growth factor requirements (Pontecorvo, 1953b). Furthermore, four dwarf mutants were picked by inspection from some of the irradiation series. The mutants were purified by micromanipulation of single conidia or by plating followed by single colony isolation.

\section{Synthesis of balanced heterokaryons}

Previous attempts by one of us (G.P.) to form balanced heterokaryons between pairs of strains each differing from the wild type in one additional nutritional requirement had been unsuccessful. A similar failure is mentioned 
by Bonner (1946) in respect of pairs of strains of Penicillium notatum; yet heterokaryosis in this species (Pontecorvo \& Gemmell, 1944; Sansome, 1947) was known to occur. The technique used in our attempts was the one which has invariably proved effective with other species of moulds (Pontecorvo, 1947, $1953 \mathrm{~b}$ ). In its most recent version it involves the following steps: (1) inoculation into liquid CM of a thick suspension of about equal numbers of conidia of each of two strains requiring different growth factors; (2) incubation for a time sufficient to obtain a thin mesh of mycelium; (3) removal of this mesh, which is washed by dipping in MM, and thoroughly broken up by teasing out over the surface of plates of MM agar; (4) incubation of these until growth starts from a few points; (5) isolation of growing hyphal tips from these points on to MM agar. The length of incubation (under 4) required for the 'escape' of the heterokaryotic growth varies with the species and with the particular pair of strains used (4 days for most combinations in Aspergillus nidulans and in A. niger).

The growth rate on agar medium of Penicillium chrysogenum is about onefifth of that of Aspergillus nidulans. It was therefore expected that the time of incubation necessary for the escape on MM agar of heterokaryotic growth would be much longer. In fact, in the unsuccessful attempts mentioned above, after 2 or 3 weeks the MM plates would begin to show widespread growth, but this proved to be syntrophic, not heterokaryotic. The conditions making it possible for balanced heterokaryotic mycelium to become established to the exclusion of, or in equilibrium with, homokaryotic mycelium have been discussed by Pontecorvo $(1953 b)$. It appeared likely that the failure just mentioned might be due to the very low growth rate of $\boldsymbol{P}$. chrysogenum. A growth rate small compared to the rate of diffusion of metabolites may not confer on the heterokaryon an advantage over the two syntrophically growing homokaryons sufficient for the heterokaryon to become established.

This kind of reasoning suggested two ways out. First, the use of pairs of strains with a very much decreased growth rate not capable of being restored to normal by the supply of growth factors; the possibility of syntrophism would thus be excluded. Strains of this type constitute an appreciable proportion of those obtained after irradiation and are identified by the tiny colonies they form even on CM agar. They will be referred to as 'dwarf' strains. Balanced heterokaryons with normal growth rate, formed between pairs of dwarf strains, have been described in other species (Dodge, 1942; Pontecorvo, 1947). Dodge's work gave, in fact, the first example of balanced heterokaryosis.

Secondly, the use of pairs of strains with more than one growth factor requirement, in order to make their metabolic interdependence in the absence of the growth factors more interlocked, and therefore presumably favouring intracellular (heterokaryotic) rather than intercellular (syntrophic) co-operation. This metabolic interlocking might be particularly effective when the growth factor requirements of the two strains are metabolically related in pairs, as in the case of different blocks on the same pathway of synthesis; e.g. requirement of adenine or hypoxanthine versus adenine only; for methio- 
nine or cystine versus methionine only. Both types of strain combinations were used and both led to the successful isolation of balanced heterokaryons, as presently described.

Balanced heterokaryons between dwarf strains. The first combination attempted between two dwarf strains was that of $22 y d w 1$ and $7 w d w 4$, i.e. of one dwarf strain with yellow conidia and requiring adenine or hypoxanthine, and another dwarf strain with white conidia and requiring cystine or thiosulphate. On MM agar, strain $7 w d w 4$ does not grow at all; strain $22 y d w 1$ grows to a barely visible size (Pl. 1, fig. 1). On CM agar $7 w d w 4$ forms very tiny dome-shaped colonies and $22 y d w 1$ irregularly shaped colonies, highly convoluted and seldom growing beyond $1 \mathrm{~cm}$. diameter (Pl. 1, fig. 1).

The balanced heterokaryon was obtained by incubating for 5 days in a testtube in liquid CM a thick mixed suspension of conidia of the two strains, removing the mycelium formed, teasing this out on the surface of MM agar plates and incubating for a further 9 days. After this time a little growth had

Table 2. Plating on supplemented medium of conidia from balanced heterokaryons in order to recover the two component types

\begin{tabular}{|c|c|c|c|c|c|}
\hline \multirow[b]{3}{*}{ Balanced heterokaryon } & & \multicolumn{4}{|c|}{ Colonies obtained } \\
\hline & & \multicolumn{2}{|c|}{ Yellow } & \multicolumn{2}{|c|}{ White } \\
\hline & Medium & No. & $\%$ & No. & $\%$ \\
\hline $\begin{array}{l}22 y d w 1+7 w d w 4 \\
22 y 13+7 w 16\end{array}$ & $\begin{array}{l}\text { CM } \\
\text { MM + adenine + methionine }\end{array}$ & $\begin{array}{r}222 \\
16\end{array}$ & $\begin{array}{r}78 \cdot 2 \\
8 \cdot 5\end{array}$ & $\begin{array}{r}62 \\
171\end{array}$ & $\begin{array}{l}21 \cdot 8 \\
91 \cdot 5\end{array}$ \\
\hline
\end{tabular}

occurred at various points, and out of some of these there grew small tufts of more vigorous mycelium with white heads. Isolation of growing tips from these tufts on to MM agar plates gave uniformly good growth with macroscopically white sporing surface (Pl. 1, fig. 1). Isolation on to CM agar gave mainly white growth of the kind just mentioned, alternating with patches obviously of $22 y d w 1$ type.

That most of the mycelium on MM agar, and most of the whitish regions of the mycelium on CM agar, were heterokaryotic and balanced was suggested by their growth rate and non-dwarf habit, and was proved by the following tests: (1) successive transfers both on MM agar and on CM agar, of hyphal tips from heterokaryons grown on MM or on CM, gave growth with the characters just described; (2) a proportion of single hyphae isolated from heterokaryons gave origin again to heterokaryotic growth; (3) platings of conidia from colonies derived from single hyphae gave the two types of parental strains: $22 y d w 1$ and $7 w d w 4$ (Table 2).

A second combination of dwarf strains was prepared from $7 w d w 5$ and $38 y d w 6$. The former has white conidia and requires cystine or thiosulphate; the latter has yellow conidia and requires $\mathrm{NH}_{4}^{+}$or $\mathrm{NO}_{\mathbf{2}}^{-}$. In this case, the heterokaryons were established by isolating small bits of more vigorous mycelium which arose at the region of contact between colonies of the two types grown on $\mathbf{C M}$ agar. These more vigorous tufts were quite evident after 
12 days from the inoculation of the plates. Evidently, even on CM agar, the heterokaryon between the two dwarf strains used had a sufficient selective advantage over either dwarf component to be able to escape from the homokaryotic mycelia.

Mass hyphal transfers on to MM agar from these more vigorous tufts grew at a rate approaching that of the wild type and developed a macroscopically yellowish sporing surface. No further work was carried out with this combination.

Following the notations used in previous papers (e.g. Pontecorvo, 1953b), heterokaryons are designated by the code numbers of the components, joined by the sign + . Thus the two heterokaryons mentioned so far will be designated: $22 y d w 1+7 w d w 4$ and $7 w d w 5+38 y d w 6$, respectively.

Balanced heterokaryons between strains each having two nutritional requirements. Balanced heterokaryons were synthesized between strains $22 y 13$ (yellow, requiring adenine or hypoxanthine, and methionine; inhibited by cystine) and $7 w 16$ (white, requiring methionine or cystine or thiosulphate, and adenine; inhibited by hypoxanthine). Neither of these two strains shows any growth on MM agar and their conidia do not even germinate on it. They both grow well on MM agar supplemented with the respective pairs of growth factors; $22 y 13$ grows well and $7 w 16$ grows poorly on CM agar.

The balanced heterokaryons $22 y 13+7$ w 16 were obtained in the same way as in the case of $7 w d w 5+38 y d w 6$, i.e. by isolation on to MM agar of tufts of vigorous mycelium arising from the region of contact between colonies of the two strains growing on CM agar. The selective advantage of the heterokaryon on CM agar may perhaps depend, in this case, on overcoming the inhibitions mentioned above.

The heterokaryon grows well on MM agar; macroscopically its sporulating surface is yellowish. The same three tests mentioned before gave proof of the heterokaryotic condition: (1) perpetuation of the heterokaryon by mass transfers of hyphae on MM agar; (2) perpetuation of the heterokaryon by single hypha isolation; (3) recovery of both component strains by plating conidia of colonies grown from single hyphae (Table 2). An additional visual test was that on addition of the appropriate growth factors to MM agar, the white, the yellow or both components would sector out.

Properties of heterokaryons. The balanced heterokaryons of Penicillium chrysogenum, in contrast with those of other species (Aspergillus nidulans, Pontecorvo, $1953 b ; A$. niger, Pontecorvo et al. 1953) can be maintained by massive transfers from the sporing surface. As in those other species, the conidia of $P$.chrysogenum are uninucleate (Tonolo \& Urbani, 1952). Thus in a heterokaryon/nuclei of each kind should segregate when the conidia are formed. That this is substantially so is shown by the results of platings of conidia at density of the order of 100 conidia/plate (Table 3). However, when plating massive numbers of conidia, rare heterokaryotic colonies arise within $48 \mathrm{hr}$, at the rate of a few per $10^{6}$ plated conidia (Table 3; Pl. 1, figs. 2, 3). It is probable that these colonies originate from bits of heterokaryotic mycelium, accidentally present in the inoculum. 
As mentioned before, one of the three heterokaryons formed (22y dw1+ $7 w d w 4$ ) has macroscopically a white sporing surface; the other two have yellowish surfaces. The structure of the penicillus in Penicillium chrysogenum, with loose and divergent conidial chains, makes it impossible to tell whether chains of different colour arise from the same conidiophore. Furthermore, the two colours (white and yellow) are not sharply distinguishable under the microscope. Nevertheless, the fact remains that all heterokaryons have, in different

Table 3. Heterozygous diploids obtained from conidia of balanced heterokaryons plated in minimal medium

\begin{tabular}{|c|c|c|c|c|c|c|c|c|}
\hline & & & & & & Diploids & letec & las† \\
\hline & Plated & conidia & $\begin{array}{r}\text { karyot } \\
\mathbf{a r} \\
\end{array}$ & $\begin{array}{l}\text { netero- } \\
\text { c colonies } \\
\text { sing* }\end{array}$ & Whole & e colonies & $\begin{array}{r}\text { Sect } \\
\text { heter }\end{array}$ & $\begin{array}{l}\text { rs from } \\
\text { karyotic } \\
\text { lonies }\end{array}$ \\
\hline $\begin{array}{c}\text { Balanced } \\
\text { heterokaryons }\end{array}$ & $\begin{array}{c}\text { Total } \\
\text { no. }\end{array}$ & $\begin{array}{l}\text { No. } \\
\text { per } \\
\text { dish }\end{array}$ & Total & $\begin{array}{l}\text { Per } 10^{6} \\
\text { plated } \\
\text { conidia }\end{array}$ & Total & $\begin{array}{l}\text { Per } 10^{7} \\
\text { plated } \\
\text { conidia }\end{array}$ & Total & $\underbrace{}_{\text {Per } 10^{2}}$ \\
\hline $\begin{array}{l}2 y d w 1+7 w d w 4 \\
2 y 13+7 w 16\end{array}$ & $\begin{array}{l}77 \times 10^{6} \\
8 \cdot 4 \times 10^{6}\end{array}$ & $\begin{array}{l}2.6 \times 10^{6} \\
0.6 \times 10^{6}\end{array}$ & $\begin{array}{r}769 \\
1083\end{array}$ & $\begin{array}{r}10 \\
138\end{array}$ & $\begin{array}{l}\mathbf{2} \\
\mathbf{3}\end{array}$ & $\begin{array}{l}\mathbf{0 \cdot 2 5} \\
\mathbf{3 \cdot 6}\end{array}$ & $\begin{array}{r}6 \\
16\end{array}$ & $\begin{array}{l}0.77 \\
1.5\end{array}$ \\
\hline
\end{tabular}

* When plating conidia of balanced heterokaryons at densities of the order of $10^{8}$ per plate a few tens of colonies arise within $48 \mathrm{hr}$. on MM. They turn out to be balanced heterokaryons, presumably arising from bits of mycelium or from rare bi- or multinucleate conidia carrying nuclei of the two kinds. Macroscopically their sporing surface is white in the case of heterokaryon (1), or yellowish in the case of heterokaryon (2), and their morphology normal (Pl. 1, figs. 2, 3).

$\dagger$ Diploids are identified either as green spored colonies of normal morphology and growth rate or as green sectors out of the newly arising heterokaryons (Pl. 1, figs. 2, 3).

proportions, both white and yellow penicilli but no green ones, while diploids (see below) have green penicilli. The colour of individual conidia seems thus to depend upon the kind of nucleus segregated into each of them. In this respect the colour markers used in $\boldsymbol{P}$. chrysogenum behave more like those used in Aspergillus nidulans (Pontecorvo, 1953 b) than like those used in $A$. niger (Pontecorvo et al. 1953).

\section{Isolation of heterozygous diploids}

Diploid from heterokaryons $22 y d w 1+7 w d w 4$. From heterokaryons grown for 2-3 weeks on MM agar, conidia (washed twice in water) were plated on MM agar at the rate of $2.6 \times 10^{6}$ conidia/plate. After $48 \mathrm{hr}$. a mean of about twenty-eight colonies/plate were visible. After a few days' further incubation all but two of these colonies developed a macroscopically visible whitish sporing surface; tests on about thirty of them showed that they were heterokaryons, as mentioned before (Table 3). Two, however, grew better than the others and developed green penicilli. Isolation, purification by single conidium micromanipulation, and further tests (see later) showed these two colonies to be the desired heterozygous diploids. Diploids are designated by interposing a fraction sign between the symbols of the strains associated in the heterokaryon which gave them origin:

$$
22 y d w 1 / 7 w d w 4 \text {, or } \frac{22 y d w 1}{7 w d w 4} \text {. }
$$


On keeping the plates for 2 weeks or more, about $1 \%$ of the heterokaryotic colonies produced one macroscopically visible green sector (Table 4 ; PI. 1, fig. 2). Isolation and tests of strains from such sectors shows them also to be diploids. Incidentally, after such prolonged incubation the plates show a background growth of minute colonies (Pl. 1, fig. 2) of type 22y dw1, presumably adapted; these minute colonies represent about $5 \%$ of the conidia of this type present in the plated suspension (Table 4).

Table 4. Properties of heterozygous diploid $22 \mathrm{y}$ dw1/7w dw4 compared with those of the heterokaryon, of the two marked haploid strains, and of the original haploid wild type Q176 (see also Pl. 1, fig. 1)

\begin{tabular}{|c|c|c|c|c|c|c|}
\hline \multirow[b]{3}{*}{ Strain } & \multirow{3}{*}{$\begin{array}{l}\text { Growth } \\
\text { habit } \\
\text { on CM }\end{array}$} & & & \multicolumn{2}{|c|}{$\begin{array}{l}\text { Growth factor } \\
\text { requirements of } \\
\text { colonies } \\
\text { arising from }\end{array}$} & \multirow{3}{*}{$\begin{array}{l}\text { Segregation } \\
\text { through conidia } \\
\text { and sectors }\end{array}$} \\
\hline & & \multicolumn{2}{|c|}{ Individual conidia } & & & \\
\hline & & Colour & Size & conidia & Hyphae & \\
\hline Q176 (haploid) & Normal & Green & Normal & None & None & None \\
\hline $22 y d w 1$ (haploid) & Dwarf & Yellow & Normal & Hypox. & Hypox. & None \\
\hline $7 w d w 4$ (haploid) & Dwarf & White & Normal & Cystine & Cystine & None \\
\hline $\begin{array}{c}22 y d w 1+7 w d w 4 \\
\text { (heterokaryon) }\end{array}$ & Normal & $\begin{array}{l}\text { White or } \\
\text { yellow }\end{array}$ & Normal & $\begin{array}{l}\text { Hypox. or } \\
\text { cystine }\end{array}$ & None & $\begin{array}{l}\text { Parental types, } \\
\text { except for very } \\
\text { rarediploids }\left(10^{-7}\right)\end{array}$ \\
\hline $\begin{array}{l}22 y d w 1 / 7 w d w 4 \\
\text { (diploid) }\end{array}$ & Normal & Green & Giant & None & None & $\begin{array}{l}\text { Small proportion } \\
\left(10^{-2}\right) \text { of parental } \\
\text { and new types }\end{array}$ \\
\hline
\end{tabular}

Diploid from heterokaryon $22 y 13+7 w 16$. From heterokaryons grown for about 2 weeks on MM agar, conidia (washed twice in water) were plated on MM agar at the rate of $0.6 \times 10^{6}$ conidia/plate. The results were similar to those of the previous example with the difference that, $(a)$ the newly arisen heterokaryotic colonies had macroscopically yellowish sporing surface; $(b)$ relative to the number of conidia plated, the proportions of newly arisen heterokaryotic colonies and of the green diploid colonies was about ten times higher (Table 4); (c) the green sectors from the heterokaryotic colonies were about twice as frequent; $(d)$ there was no delayed background growth of parental types (Pl. 1, fig. 3). Isolation from one of the green colonies, purification by single conidium micromanipulation and further tests led to the establishment of diploid $22 y 13 / 7$ w 16.

Properties of diploids. The diploids differ from the heterokaryons, from the haploids which formed the heterokaryons and from the haploid wild type in a number of ways. These have been tabulated (Table 5) for the case of diploid $22 y d w 1 / 7 w d w 4$ and some of them are evident on Pl. 1, fig. 1. These differences also apply, mutatis mutandis, to the case of diploid $22 y 13 / 7 w 16$. The size of the conidia is not easily measurable because of considerable variations in shape. However, a visual comparison (Pl. 1, fig. 4) leaves no doubt that diploids have larger conidia, a fact suggesting that Sansome (1949) was right when she deduced that the 'gigas' strains isolated by her in the closely related species Penicillium notatum were (homozygous) diploid. As diploids heterozygous for nutritional 
requirements, colours of conidia and habit of growth, show features approaching those of the wild type (no requirement, green conidia and normal growth) all the mutant properties used as markers in this work are recessive. In the diploids segregation and recombination take place, as shown in detail in the next section, i.e. a small proportion of individual conidia or hyphae of the diploids give rise to strains different from the diploid from which they arose, in that they show one or more properties of the original marked strains associated either in the original way or in new ways.

Table 5. First-order segregants from diploid:

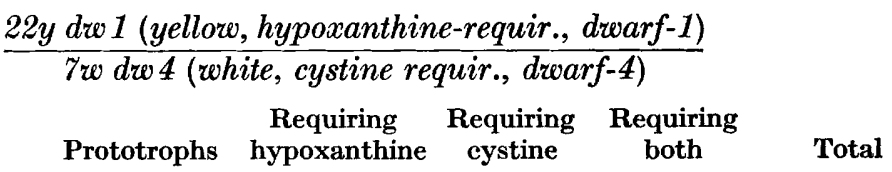

\begin{tabular}{|c|c|c|c|c|c|}
\hline \multirow{2}{*}{\multicolumn{6}{|c|}{ A. Obtained as whole colonies* }} \\
\hline & \\
\hline & $\mathbf{5}$ & 0 & $\mathbf{0}$ & $\mathbf{0}$ & $\mathbf{5}$ \\
\hline Normal & 964 & 1 & $\mathbf{0}$ & $\mathbf{0}$ & 965 \\
\hline \multicolumn{6}{|l|}{ Yellow } \\
\hline Dwarf & 2 & 1 & $\mathbf{0}$ & $\mathbf{0}$ & $\mathbf{3}$ \\
\hline Normal & 2 & $\mathbf{0}$ & $\mathbf{0}$ & $\mathbf{0}$ & $\mathbf{2}$ \\
\hline \multicolumn{6}{|l|}{ White } \\
\hline Dwarf & 6 & $\mathbf{0}$ & $\mathbf{0}$ & $\mathbf{0}$ & 6 \\
\hline Normal & 12 & $\mathbf{0}$ & $\mathbf{0}$ & $\mathbf{0}$ & 12 \\
\hline \multicolumn{6}{|c|}{ Non-sporing } \\
\hline Normal & 17 & $\mathbf{0}$ & $\mathbf{0}$ & $\mathbf{0}$ & 17 \\
\hline & 1008 & $\mathbf{2}$ & $\mathbf{0}$ & $\mathbf{0}$ & 1010 \\
\hline
\end{tabular}

\begin{tabular}{|c|c|c|c|c|c|}
\hline \multicolumn{6}{|l|}{ Green } \\
\hline Dwarf & 0 & 0 & 0 & 0 & 0 \\
\hline Normal & 0 & 0 & 1t & 0 & 1 \\
\hline Dwarf & 1 & 0 & 0 & $\mathbf{0}$ & 1 \\
\hline \multicolumn{6}{|l|}{ Yellow } \\
\hline Normal & $\mathbf{5}$ & 0 & $\mathbf{0}$ & 0 & 5 \\
\hline \multicolumn{6}{|l|}{ White } \\
\hline Dwarf & $\mathbf{0}$ & 0 & 0 & $\mathbf{0}$ & 0 \\
\hline \multirow[t]{2}{*}{ Normal } & 14 & 0 & 0 & 0 & 14 \\
\hline & 20 & o & 1 & 0 & 21 \\
\hline
\end{tabular}

* Conidia of $22 y d w 1 / 7 w d w 4$ were plated on CM, and 1010 colonies were classified as to colour, morphology and requirements.

+ Sectors, differing in colour or growth habit from the mother colonies, were isolated from a proportion of the 964 green, normal, prototroph colonies, and classified as to colour, morphology and requirements.

$\ddagger$ Though this sector had green conidia and non-drawf habit, it was isolated because of its rather thinner growth than the rest of the mother colony: it turned out to be cystinerequiring.

Segregation and recombination in diploids

In Aspergillus nidulans and A. niger (Pontecorvo \& Roper, 1953; Pontecorvo et al. 1953; Pontecorvo et al. 1954) mitotic segregation and recombination occurs once about every 100 divisions in heterozygous diploids. Its detectable result is the production of diploid nuclei homozygous for one or more of the recessive 
markers or of haploid nuclei with one or more of the recessive markers. A patch of mycelium homokaryotic for one of these nuclei (for short, 'segregant' nuclei) will have the recessive marker property or properties. When these properties are detectable by inspection (e.g. colour of conidia) the patch of mycelium may be identified visually and a strain isolated from it. In the two other species mentioned above this visual identification is easy even in the case of a single head in a background of thousands with the wild type colour. In Penicillium chrysogenum individual heads differing in colour from the background are difficult to recognize, and only patches of homokaryotic segregant mycelium with a substantial number of segregant heads can be identified visually and isolated.

Thus one way of detecting mitotic segregation and recombination of colour markers is to examine a number of diploid colonies (preferably originated from single conidia) for the presence of sectors with penicilli of one of the recessive colours; isolation from these patches will permit the classification of each segregant in respect of other properties also (e.g. nutritional requirements, growth habit, etc.). Another way in which segregation, not only of colour markers but of any markers, can be recognized is by plating conidia of the diploid and classifying individually the resulting colonies. This classification can be visual as to colour of conidia and growth habit, but requires the testing of individual colonies for nutritional requirements. Segregation and recombination was analysed extensively in the case of diploid $22 y d w 1 / \%$ w dw 4 (see later). As to diploid 22y13/7w16, we only went so far as to observe that it did segregate for colour markers. An extensive analysis of this and other diploids was carried out later at the Istituto Superiore di Sanitá, Rome, by one of us (G. S.), and it will be the subject of a separate publication.

First-order segregants. First-order segregants from diploid $22 y d w 1 / 7 w d w 4$ were obtained by plating conidia of a subculture (purified by single conidium micromanipulation) on fully supplemented medium; 1010 colonies (Table 5) from this plating were transferred to plates of minimal agar. After 2 days those colonies which showed no further growth were picked out and tested for nutritional requirements and colour. The remaining colonies were transferred back on to supplemented medium, kept until the colour appeared on the sporing surface, and then classified for colour and morphology.

A proportion of the 964 green prototroph normal colonies (out of the total of 1010) showed sectors; some were yellow, some white and some nonsporulating or with a growth habit different from that of the mother colony. Twenty-one of these sectors were isolated, each from a different colony, and further tested. Table 5 shows the classification of the forty-six segregants obtained as whole colonies after plating, and of the twenty-one segregants detected as sectors in some of the colonies arising from platings. The proportion of segregants among the conidia of the diploid is about $5 \%(46 / 1010)$. No recombination of parental recessive characters occurred among the sixtyseven first-order segregants isolated either as colonies or as sectors (Table 5).

Second-order segregants. The first-order segregant with green conidia, normal growth and hypoxanthine requirement was tested for further segregation after 
purification by single conidium isolation. One yellow and two white sectors from colonies of this strain gave yellow or white, hypoxanthine-requiring strains, with normal growth. A white hypoxanthine-requiring strain is an example of recombination between recessive properties of the starting strains.

\section{CONCLUSIONS}

The experiments reported show the occurrence in Penicillium chrysogenum of the parasexual processes already found in two other species of filamentous fungi. In Penicillium the analysis has gone only so far as to identify three out of the four steps which were studied in detail in the two other species, namely: (1) formation of heterokaryons; (2) formation of heterozygous diploid nuclei within heterokaryons; (3) recombination in the diploid nuclei. We have not yet looked for and identified the formation of haploid nuclei from diploid nuclei (Pontecorvo et al. 1953a; Pontecorvo, 1954). As, however, this is a consequence of accidents of mitosis of a type known to occur in all higher and lower organisms in which it has been looked for, it is a reasonable assumption that it will be found also in Penicillium.

Penicillium thus may have, like the two other species, a complete parasexual cycle (Pontecorvo, 1953a). This involves alternation of haploid and diploid stages, the possibility of storing gene variation under the cloak of dominance in both heterokaryons and heterozygotes and the possibility of gene recombination.

Because of its low growth rate and certain details of its morphology, Penicillium chrysogenum is a species much less suitable than Aspergillus nidulans or $A$. niger for the detailed analysis of the parasexual processes themselves. It is, however, a species of great economic importance. The discovery of the parasexual processes in it is relevant in two respects. First, this third species of filamentous fungus again shows the occurrence of these parasexual processes; thus they would appear to be widespread at least. Secondly, the parasexual processes in $\boldsymbol{P}$. chrysogenum can be used for practical purposes: (a) deliberate 'crossbreeding' for the production of improved industrial strains; $(b)$ the identification of different genetic blocks in the analysis of the biosynthesis of penicillin.

One of us (G.S.) is indebted to the Istituto Superiore di Sanitá, Rome, for a grant enabling him to take part in this work at the Department of Genetics, University of Glasgow. This work is part of a general programme supported by the Nuffield Foundation.

\section{REFERENCES}

Bonner, D. (1946). Production of biochemical mutations in Penicillium. Amer. J. Bot. 33, 788.

Dodge, B. O. (1942). Heterokaryotic vigor in Neurospora. Bull. Torrey bot. Cl. 69, 75. Ponteconvo, G. (1947). Genetic systems based on heterokaryosis. Cold Spr. Harb. Symp. quant. Biol. 11, 193.

Pontecorvo, G. (1952). Non-random distribution of multiple mitotic crossing-over among nuclei of heterozygous diploid Aspergillus. Nature, Lond. 170, 204.

Pontecorvo, G. (1953a). Mitotic recombination in the genetic systems of filamentous fungi. Proc. IXth Intern. Congr. Genetics (in the Press).

Ponteconvo, G. (1953b). The genetics of Aspergillus nidulans. Advanc. Genet. 5,141 . 
Ponteconvo, G. \& Gemmel, A. R. (1944). Genetic proof of heterokaryosis in Penicillium notatum. Nature, Lond. 154, 514 .

Pontecorvo, G. \& Roper, J. A. (1952). Genetic analysis without sexual reproduction by means of polyploidy in Aspergillus nidulans. J. gen. Microbiol. 6, vii.

Pontecorvo, G. \& Roper, J. A. (1953). Diploids and mitotic recombination. Advanc. Genet. 5, 218.

Pontecorvo, G., Roper, J. A. \& Forbes, E. (1953). Genetic recombination without sexual reproduction in Aspergillus niger. J. gen. Microbiol. 8, 198.

Ponteconvo, G. \& Sermontr, G. (1953). Recombination without sexual reproduction in Penicillium chrysogenum. Nature, Lond. 172, 126.

Pontecorvo, G., Tarr Gloor, E. \& Forbes, E. (1954). Analysis of mitotic recombination in Aspergillus nidulans. J. Genet. 52, $22 b$.

Roper, J. A. (1952). Production of heterozygous diploids in filamentous fungi. Experientia, 8, 14.

Sansome, E. (1947). Spontaneous variation in Penicillium notatum. Trans. Brit. mycol. Soc. 31, 66.

Sansome, E. (1949). Spontaneous mutation in standard and 'Gigas' forms of Penicillium notatum. Trans. Brit. mycol. Soc. 32, 305.

Tonolo, A. \& Urbani, E. (1952). Observations on Penicillium chrysogenum in submerged culture. Bull. World Hith Org. 6, 277.

\section{EXPLANATION OF PLATE}

Fig. 1. +, the haploid green wild type; 1 , the haploid dwarf, yellow, hypoxanthine-requiring $22 y d w 1 ; 4$, the haploid dwarf, white, cystine-requiring $7 w d w 4 ; \mathrm{HK}$, the heterokaryon between $22 y d w 1$ and $7 w d w 4 ; \mathrm{D}$, the diploid derived from the heterokaryon. Left: on complete medium. Right: on minimal medium. White circles indicate the positions of inoculum on MM of the two dwarf strains.

Fig. 2. Plating on MM of conidia of heterokaryon $22 y d w 1+7 w d w 4\left(2 \cdot 6 \times 10^{8} / \mathrm{dish}\right)$ : there are about twenty heterokaryotic colonies (large) per dish, and a background of minute colonies of type $22 y d w 1$. About $1 \%$ of the heterokaryotic colonies show, like the one in the centre, a green diploid sector.

Fig. 3. Plating on MM of conidia of heterokaryon $22 y 13+7 \mathrm{w} 16$ : results similar to those of Fig. 2, but no background growth. Two heterokaryotic colonies show green diploid sector.

Fig. 4. Conidia of heterokaryon $22 y d w 1+7 w d w 4$ (left) and of the diploid derived from it (right) about $\times 400$. 
Journal of General Microbiology, Vol. 11, No. 1

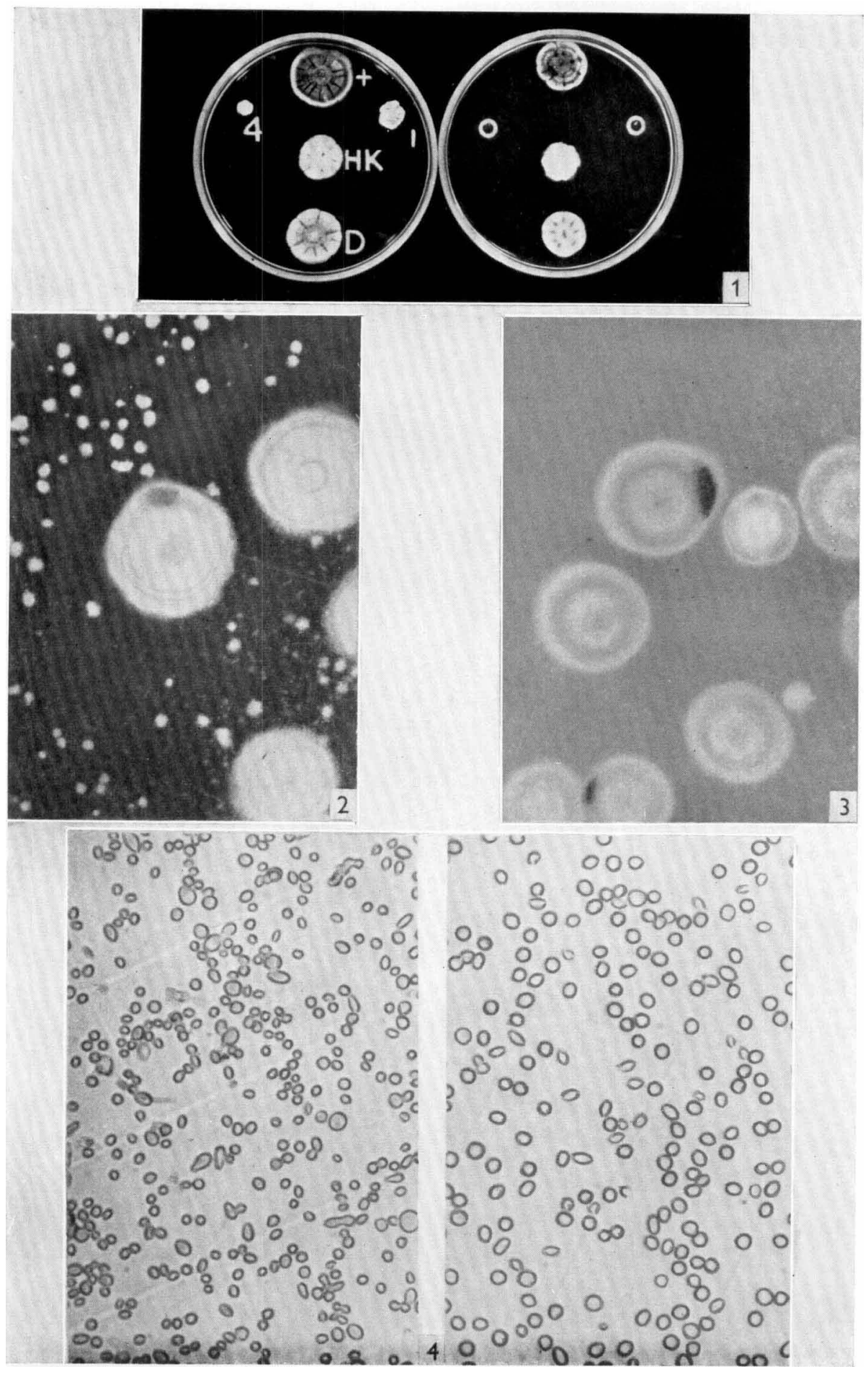

G. Ponteconvo \& G. Sermonti--Parasexual recombination 